\title{
El contrato estatal de prestación de servicios personales y el principio de la primacía de la realidad
}

\section{Bertha Lucy Ceballos Posada}

Abogada de la Universidad del Cauca, Especialista en Derecho administrativo y en Derecho Laboral y Relaciones Industriales; estudios de primer y segundo ciclo del Doctorado en Derecho de la Universidad de Barcelona, Profesora e investigadora de la Universidad Surcolombiana.

\section{Resumen}

En las actuales reformas para la modernización del Estado, la supresión de cargos es herramienta necesaria para la viabilidad financiera. Sin embargo, se viene asumiendo que las actividades de quienes ejercieron los cargos suprimidos pueden ser reemplazadas mediante la vinculación contractual de servicios personales, sin que ello pueda generar la reclamación de derechos laborales, tesis que la Sala Plena del Consejo de Estado ha elaborado bajo presupuestos que en este ensayo se critican, a la luz de los enunciados y argumentos que concretan los principios fundamentales del derecho del trabajo establecidos en nuestro actual sistema jurídico.

\section{Palabras claves}

Contrato estatal de prestación de servicios personales. Reestructuración del Estado.

\section{Abstract}

In the present reforms for the State upgrade, the post suppression is a necessary tool for the surety financial. However, it is taken on that the activities of those post eliminated can be replaced with the contractual entail of personal services, without the possibility to reclaim labor rights. Thesis that the Consejo de Estado has done under reasoning that in this rehearsal are criticized, in the light of the arguments that boil down the essential labor rights established in our present law system. 


\section{Presentación}

Quien tiene con el Estado una verdadera relación laboral, pero esta formalmente vinculado mediante un contrato estatal, bajo la actual jurisprudencia del Consejo de Estado, no puede reclamar los derechos laborales que surgen de dicha relación.

A partir de la sentencia de la Sala plena del Consejo de Estado ${ }^{7}$ que rectifica su jurisprudencia en el tema, se hace necesario abordar la temática, para lo cual en este ensayo se presenta un análisis de los últimos pronunciamientos en la materia, con la necesaria crítica ante los efectos que tal jurisprudencia representa en las actuales circunstancias de ejecución del plan de modernización del estado y adecuación a las políticas de ajuste fiscal.

En la citada sentencia, el Consejo de Estado concluye que las exigencias y condiciones normativamente previstas para el empleo público no pueden quebrantarse por la figura del contrato realidad, es decir, cuando evidentemente la prestación contractual ha correspondido a una verdadera relación laboral.

Los efectos de esta modificación jurisprudencial repercuten en el ámbito de las relaciones de la función pública de las entidades estatales, pues legitiman la existencia de verdaderas relaciones laborales irregulares y precarias que desconocen los derechos mínimos del trabajador, cuyos efectos anteriormente eran corregidos en sede jurisdiccional, mediante la condena al pago de las acreencias laborales no reconocidas por la administración.

Se presentan así, argumentos adicionales a los de las aclaraciones y salvamentos de voto ${ }^{8}$ de la referida sentencia, para concluir que la existencia de una relación laboral no puede ser desconocida ni siquiera bajo el fundamento del carácter especial de las normas que regulan la función pública.

\footnotetext{
${ }^{7}$ Sentencia del 18 de noviembre de 2003, radicación IJ-39 de 2003, C.P. Nicolás Pajaro Peñaranda.

${ }^{8}$ Aclaración de voto del Consejero Darío Quiñones Pinilla. Salvedad de voto de los magistrados:

Alberto Arango Mantilla, Germán Ayala Mantilla, Maria Elena Giraldo Gómez, Filemón Jiménez

Ochoa, Ramiro Saavedra Becerra, Alejandro Ordoñez Maldonado. Salvamento unificado, suscrito

el 11 de diciembre de 2003 por los magistrados: Ricardo Hoyos Duque, Germán Rodríguez Villamizar, Alier Eduardo Hernández Enríquez y Jesús María Lemos B.
} 


\section{Las tesis de la sentencia y su crítica}

Como antecedente fáctico se tiene que la acción se presentó por una persona natural contratada por la Dirección Seccional de la Administración Judicial de Caldas para desarrollar actividades de mantenimiento y aseo de su sede, quien solicita la nulidad de los actos administrativos que negaron el reconocimiento de prestaciones laborales y reclama el restablecimiento del derecho mediante la condena al pago de tales prestaciones.

\section{La licitud del contrato estatal de prestación de servicios}

Para el Consejo de Estado, el artículo 32 numeral 3 de la Ley 80 de $1993^{9}$ faculta a la administración a suscribir tales contratos cuando las actividades no puedan desarrollarse por el personal de la planta, o cuando se requiera de conocimientos especializados, en cuyo caso el contrato será transitorio, y no generará relación laboral alguna.

Los salvamentos de voto advierten que la exequibilidad de dicha norma fue condicionada por la Corte constitucional cuando, bajo la aplicación del principio de la primacía de la realidad sobre las formalidades establecidas. Excluyó del concepto de contrato estatal de prestación de servicios el evento en que «se acredite por parte del contratista la existencia de una relación laboral subordinada».

Lo anterior significa que la sola ausencia del cargo en la planta de personal no faculta a la administración para acudir a la figura formal del contrato estatal con el propósito de evadir los pagos laborales. De aplicarse dicha tesis, las plantas de personal de las entidades públicas podrían reducirse ampliamente, con el único objetivo de disminuir los gastos operativos en los rubros de servicios personales, que suelen representar un peso mayoritario en todo presupuesto público.

La tesis del Consejo de Estado niega la efectividad de los derechos y las garantías

\footnotetext{
${ }^{9}$ Art. 32 Ley 80 de 1993: Son contratos estatales todos los actos jurídicos generadores de obligaciones que celebren las entidades a que se refiere el presente estatuto, previstos en el derecho privado o en disposiciones especiales, o derivadas del ejercicio de la autonomía de la voluntad, así como los que, a título enunciativo, se definen a continuación:...

$3^{o}$. Contrato de prestación de servicios: Son contratos de prestación de servicios los que celebren las entidades estatales para desarrollar actividades relacionadas con la administración o funcionamiento de la entidad. Estos contratos sólo podrán celebrarse con personas naturales cuando dichas actividades no puedan realizarse con personal de planta o requieran conocimientos especializados. En ningún caso estos contratos generan relación laboral ni prestaciones laborales y se celebrarán por el término estrictamente indispensable.
} 
mínimas del trabajador, reunidos en el artículo 53 de la Carta Política colombiana, y reconocidos en instrumentos internacionales tales como los contenidos en la Declaración universal de Derechos Humanos, el Pacto Internacional de Derechos Económicos, Sociales y Culturales de 1966 aprobado mediante la ley 74 de 1968, y los Convenios 87, 98, 100 y 111 de la O.I.T. aprobados a través de las leyes 26 y 27 de 1976, 54 de 1962 y 22 de 1967, respectivamente.

Resulta contraria a tales ordenamientos, cuando bajo la supuesta autorización legal para crear relaciones laborales transitorias en ausencia del cargo, se vulnera el principio de la igualdad, discriminándose al contratista frente al servidor que ejecutando igual labor, por el hecho de ejercer un empleo público, sería el único autorizado a recibir las prestaciones laborales consagradas en la ley, discriminación definida para el contexto laboral como una exclusión y restricción al uso y goce de bienes y servicios disponibles, generando severas repercusiones en el campo inmaterial ${ }^{10}$.

También se vulnera el deber constitucional del juez de aplicar el principio de la primacía de la realidad sobre las formalidades existentes, lo que conforme a la doctrina exige que «en caso de discordancia entre lo que ocurre en la práctica y lo que surge de los documentos o acuerdos, debe darse preferencia a lo primero $^{11}{ }$. Este principio, que se fundamenta en el aforismo civilista según el cual «las cosas son lo que su naturaleza y no su denominación determina», es un mecanismo de preservación del sistema laboral, que hace efectiva la protección constitucional al Trabajo, considerado como un deber y un derecho; como la base del bienestar social; como un medio de la realización de la persona y como un objeto de atención prioritaria del Estado.

La Corte Suprema de Justicia, al referirse a la aplicación del principio, agrega que «busca el imperio de la buena fe» y aclara que rige aún antes de su actual

\footnotetext{
${ }^{10}$ CONTI PARRA.. Augusto. Discriminación en el empleo. Bogotá: Librería Jurídica Gustavo Ibáñez, 1 edición 1995.

${ }^{11}$ PLA RODRIGUEZ, Américo. Cursillo sobre el Derecho del Trabajo y los Funcionarios Públicos. Montevideo: Edit. MBA, 1977. Además, la Sentencia de 27 de octubre de 1998 de la Corte Suprema de justicia Sala de Casación Laboral, establece: «La primacía de la realidad contemplada por el articulo53 de la Constitución Nacional, implica que los juzgadores, en materia laboral no se hallan atados por las informaciones que se desprenden de los documentos o actos jurídicos celebrados por las partes de las relaciones de trabajo, aunque estas hayan actuado de buena Je, de suerte que esdable que desechen esas informaciones si encuentran la evidencia de una realidad diferente que requiera de la aplicación de la ley laboral o su aplicación correcta, según el propósito del legislador. Por lo tanto, no sólo cuando aparezcan vicios del consentimiento o fraudes a la ley, es dable desconocer conveníos y acuerdos de los contratantes laborales que contraríen la realidad, sino en cualquier caso que esa contrariedad se acredite».
} 
consagración constitucional en el artículo 53, cuando por vía doctrinaria y jurisprudencial se construyó para la material laboral ${ }^{12}$.

Vistas las anteriores razones, resulta contradictorio el argumento de la sentencia del Consejo de Estado comentada cuando indica:

«El principio de la primacía de la realidad sobre las formalidades establecidas por los sujetos de las relaciones laborales, no tiene, adicionalmente el alcance de excusar con la mera prestación efectiva del trabajo la omisión del cumplimiento de los requisitos constitucionales y legales previstos para acceder a la función pública, que en la modalidad estatutaria son el nombramiento y la posesión»

La anterior tesis además, ya se había enunciado antes por la Corporación, y como muestra se cita la sentencia de su Sección Segunda ${ }^{13}$, cuando con motivo de la reclamación de un músico profesional vinculado como contratista a la Banda Departamental del Cesar, absolvió a la demandada y concluyó que «es dable celebrar contratos de prestación de servicios, cuando la planta de personal no alcance para atender eficientemente el funcionamiento normal o excepcional de la entidad y adicionalmente como otro evento aparte, cuando se requieran conocimientos especializados». (Subrayas adicionales).

Y mayor contrariedad se presenta cuando la misma Sección Segunda del Consejo de Estado, en sentencias posteriores, retoma la vigencia de la figura doctrinaria del funcionario de hecho ${ }^{14}$, para admitir que, por excepción, tal figura surge «como forma de vinculación a la administración pública., por el desempeño de una función en virtud de una figura irregular... por la precariedad de algunos elementos que formalmente se requieren para predicar cabalmente la noción de empleado público, es decir, nace por defecto o imperfección de una formalidad que no se cumplió», o vuelve a la tesis de la demostración de los elementos de la relación de trabajo ${ }^{15}$.

De este modo, la verdadera interpretación que surge de la previsión legal en cuanto a la contratación de prestación de servicios es que, bajo la condición de ausencia de cargos en la planta, el contratista que se vincule lo será sin mediar la

\footnotetext{
${ }^{12}$ Sala de Casación Laboral, sentencia 22259 de agosto 2 de 2004, M.P. Luis Javier Osorio López.

${ }^{13}$ Consejo de Estado, Sala de lo Contencioso Administrativo, sentencia del 18 de septiembre de 2003, Consejero Ponente: Tarsicio Cáseres Toro, Rad. 3526-01.

${ }^{14}$ Sentencia del 15 de julio de 2004, C.P. Alejandro Ordoñez Maldonado, con aclaración de voto de Nicolás Pájaro Peñaranda.

${ }^{15}$ Sentencia de 19 de febrero de 2004. Expediente 0099-03, C.P. Alejandro Ordoñez Maldonado.
} 
subordinación, dependencia y permanencia propias de la relación laboral, conforme lo desarrolló la Corte Constitucional ${ }^{16}$, es decir, bajo su autonomía e independencia como elementos esenciales ${ }^{17}$, donde la prestación se realice de manera transitoria.

Dicha previsión de la Ley 80 corresponde además a los criterios de administración de personal propios de toda empresa, tales como la necesidad de disponer del recurso humano debido, incluyéndose en ello los cargos misionales, es decir, los que permiten ejecutar la esencia de los servicios, y los cargos operativos que contribuyen en forma conexa a los primeros.

En la materia, la Corte Suprema de Justicia reiteradamente ha sostenido que la sola existencia de contratos de prestación de servicios estatales «no descarta de plano, la existencia de un contrato de trabajo (relación laboral para los empleados públicos), así como tampoco permite sostener por esa sola circunstancia, que tal deducción constituya una equivocación protuberante» ${ }^{18}$, mientras que la Subsección B de la Sección Segunda del Consejo de Estado ${ }^{19}$, acudió a igual argumento para determinar la competencia sobre controversias laborales en las que medie un contrato de prestación de servicios.

Además, la existencia del contrato estatal de prestación de servicios que esconde una relación de trabajo para la Corte Suprema de Justicia constituye causa de exoneración de la indemnización moratoria consagrada en el artículo 57 del Decreto 2127 de 1945 para los trabajadores oficiales, bajo el criterio de que esta circunstancia por sí sola no es determinante de la existencia de mala fe del empleador $^{20}$.

De tal manera que no existe autorización legal para desconocer derechos laborales cuando su causa sea una relación de trabajo, cualquiera sea su nombre o modalidad, especialmente ante la forma del contrato estatal de prestación de servicios personales.

\footnotetext{
${ }^{16}$ Corte Constitucional, Sentencia C-056/93, M.P. Dr. Eduardo Cifuentes Muñoz.

${ }^{17}$ Consejo de Estado, Sala de lo Contencioso Administrativo, Sección segunda, Subsección B, Radiación 2653-01, 17 de junio de 2004, C.P. Dr. Alejandro Ordoñez Maldonado

${ }^{18}$ Sentencia del 28 de julio de 2004, M.P. Isaura Vargas Díaz que en lo pertinente además cita las Sentencias del 11 de diciembre de 1997 Rad. 10.153 y del 22 de marzo de 2000, Rad. 12960.

${ }^{19}$ Consejo de Estado, Sala de lo Contencioso Administrativo, sentencia del 18 de septiembre de 2003, Consejero Ponente: Tarsicio Cáseres Toro, Rad. 3526-01.

${ }^{20}$ Sentencia del 28 de julio de 2004, M.P. Isaura Vargas Díaz.
} 


\section{La subordinación como elemento esencial de la relación laboral}

Lo que se exige para reclamar una relación laboral ante la existencia de un contrato de prestación de servicios, es la concurrencia de los elementos propios de aquélla, entre ellos la prestación personal del servicio, la remuneración económica que constituirá el salario, y la continuada subordinación.

En este punto de la subordinación, para la jurisprudencia actual del Consejo de Estado $^{21}$ podemos destacar las siguientes variaciones:

1. «La subordinación se materializa en el cumplimiento de órdenes, la sujeción a un horario de trabajo ${ }^{22}$, el sometimiento a metas, objetivos y directrices».

2. La labor ha de ser habitual, es decir, «constante y cotidiana, que conlleve el cumplimiento de un horario de trabajo, no necesariamente durante todos los días de la semana, sino algunos, siempre y cuando la labor se realice frecuentemente en los días acordados» ${ }^{23}$.

3. Las relaciones de coordinación entre la administración y el contratista no son iguales a las relaciones de subordinación. Aquéllas implican la posibilidad de que la administración imponga tareas técnicas, una disponibilidad horaria específica, la obligación de rendir informes ${ }^{24}$, o la necesidad de someter al contratista a las pautas y a la forma como en la administración se encuentran coordinadas las distintas actividades, sin que se afecte la autonomía del contratista $^{25}$.

De esta manera, para el punto de la subordinación, se requiere analizar en cada caso concreto, la forma como se dieron las relaciones de prestación, deslindando así la existencia de relaciones de coordinación con las de subordinación, las que se distinguirían por un mayor poder de limitar la autonomía del contratista, bien sea mediante la formulación de órdenes (no sólo directrices o pautas), o por la imposición de verdaderas sanciones disciplinarias, por ejemplo.

\footnotetext{
${ }^{21}$ Con adiciones a las tesis que había expuesto en Sentencia del 9 de agosto de 2001, Expediente 0846-01, Sección Segunda, Subsección B.

${ }^{22}$ Sin que el sólo sometimiento a un horario de trabajo sea único criterio, como se advierte en sentencia del 19 de febrero de 2004, Exp. 0099-03. C.P. Dr. Alejandro Ordoñez Maldonado.

23 ídem.

${ }^{24}$ Sala de lo Contencioso Administrativo, Sección Segunda, Subsección B, sentencia del 17 de junio de 2004, Rad. 2653-01 ,C.P. Alejandro Ordoñez Maldonado.

${ }^{25}$ Igual a cita 1.
} 
Habrá de demostrarse entonces, situaciones como las siguientes ${ }^{26}$ :

- Que la actividad del contratista es similar o igual a la que cumple un servidor de planta de la misma entidad.

- Llamados de atención u órdenes expresas recibidas por el contratista.

- Asignación de actividades que implicaban subordinación y dependencia.

- Similitud entre el valor de los honorarios del contratista y la remuneración prevista para los servidores con las funciones parecidas a las que aquél desarrolla.

- Entrega de tareas e informes que eran objeto de revisión o corrección.

- Celebración de varios contratos en períodos próximos (sin solución de continuidad).

En cuanto al aspecto probatorio, el Consejo de Estado advierte que los testimonios de personas que se encuentren en la misma situación que el demandante, esto es, que también desarrollaron o cumplen actividades como contratistas de prestación de servicios, no tienen suficiente valor probatorio pues carecen de imparcialidad al tratarse de «declarantes que ostentan interés en el mismo proceso», debiendo entonces acudirse a otros medios de prueba que en efecto demuestren el elemento de la subordinación ${ }^{27}$, argumento que resulta contrario a la regulación legal sobre la materia pues los artículos 187 y 217 del C.P.C., al referirse a la sana crítica como sistema de valoración de las pruebas exige que para la valoración de los dichos de aquellos testigos que se califiquen como sospechosos, deberá el juez tener más cuidado, pero no desconocerlos o eliminarlos de plano.

Se espera pues, que la jurisprudencia laboral administrativa desarrolle en adelante con mayor precisión la definición del concepto de relaciones de coordinación y su distinción con las relaciones de subordinación, pues sobre la materia, la Corte Suprema de Justicia, independientemente de que se trate de función pública o relación de naturaleza privada, mantiene la definición de la subordinación como la «aptitud o facultad del empleador de dar órdenes o instrucciones al trabajador y de vigilar su cumplimiento en cualquier momento durante la ejecución del contrato y la obligación permanente del asalariado de obedecerlas y acatarlas cumplidamente» ${ }^{28}$, incluyendo para el efecto las

\footnotetext{
${ }^{26}$ Consejo de Estado, Sala Contencioso Administrativa, Sección Segunda, sentencia del 21 de octubre de 2002, Ref: 1420-2001 reiterada en Sentencia del 19 de febrero de 2004, expediente 0099-03, C.P. Dr. Alejandro Ordoñez Maldonado.

${ }^{27}$ Sentencia del 28 de noviembre de 2002, Ref. 0804-2002, C.P. Alejandro Ordñoez Maldonado reiterada en sentencia de 19 de febrero de 2004, Exp. 0099-03, C.P. Alejandro Ordoñez Maldonado. Además: sentencia del 18 de septiembre de 2003, Ref. 01678-98, C.P. Tarsicio Cáceres Toro.

${ }^{28}$ Sala de Casación Laboral, sentencia de julio 01 de 1994, Rad. 6258 reiterada en Sentencia del
} 
características ya enunciadas para las relaciones de coordinación que distingue el Consejo de Estado.

En lo específico, refiere la Sala de Casación Laboral que tal subordinación implica que el contratista tiene las obligaciones de «cumplir órdenes; entre ellas el horario (como limitante de la «libre distribución y uso del tiempo»), como el asistir a reuniones y la disponibilidad para con el empleador («que se distingue por la preponderancia del sometimiento y dependencia para con la demandada») $)^{29}$.

La Corte además, para el caso de los contratos estatales que esconden una relación laboral con trabajador oficial, aplica la figura del plazo presuntivo de seis meses prevista para los contratos de trabajo con dichos servidores en el artículo 4 del Decreto 2127 de 1945, ordenando la indemnización por terminación unilateral injustificada por el plazo faltante para tal fin, a menos que se pruebe en debida forma la existencia de norma convencional que ordene al reintegro $^{30}$.

Sin embargo, como glosa característica de la técnica de la casación en la jurisdicción ordinaria, es menester que cuando se alega la existencia de una situación laboral típica de trabajadores oficiales, la argumentación del cargo se fundamente sobre las normas específicas de la función pública que rigen la materia, y no sobre el Código Sustantivo del Trabajo ${ }^{31}$.

Por su parte, la Corte Constitucional ${ }^{32}$ desarrolla la subordinación jurídica, como la facultad del empleador «para exigir el cumplimiento de órdenes en cualquier momento, respecto al modo, tiempo o cantidad de trabajo e imponer reglamentos internos de trabajo», subordinación o dependencia que «debe ser continuada -que no quiere significar que sea ejercida en forma continua, lo que sería físicamente imposible de realizar-, en tanto que pueda ejercerse por el empleador en cualquier momento y mientras dure el contrato».

\section{El efecto sobre el contrato estatal que esconde una relación laboral}

02 de agosto de 2004, Radicación 22259, M.P. Dr. Luis Javier Osorio López.

${ }^{29}$ Sentencia del 02 de agosto de 2004, Radicación 22259, M.P. Dr. Luis Javier Osorio López

${ }^{30}$ Sentencia del 28 de julio de 2004, Rad. 21491, M.P. Isaura Vargas Díaz, demandado: I.S.S.

Seccional Antioquia

${ }^{31}$ Corte Suprema de Justicia, Sala de Casación Laboral, Sentencia del 20 de mayo de 2004, M.P.

Isaura Vargas Díaz. Demandado: I.S.S.

${ }^{32}$ Sentencia C-1110 de 24 de octubre de 2001, M.P. Clara Inés Vargas Hernández. 
Volviendo a la jurisprudencia del Consejo de Estado, la Sala Plena explica que anteriormente se consideraba que el contrato de prestación de servicios con verdadero objeto laboral era inexistente, al contrariar la primacía de la realidad, lo cual corresponde al «objeto moralmente imposible» consagrado en el artículo 1.518 del Código Civil. El carácter de inexistente implica que no se requiera pronunciamiento judicial alguno para invalidar lo que no existe.

Pero en su nueva tesis, la sala plena rectifica su jurisprudencia, indicando que tal efecto no será la inexistencia, sino la nulidad del contrato, en aplicación de los artículos $1.741,1.523$ y $1.519^{33}$ del Código Civil, que desarrollan la causa y el objeto ilícitos como causal de nulidad absoluta del contrato, la cual sí requiere pronunciamiento judicial.

Los salvamentos de voto no se refieren a este punto en concreto, y a pesar de coincidirse con la nueva doctrina, resulta necesario analizar sus efectos, ya que desde el punto de vista procesal, la invalidez del contrato se pretende mediante la acción contractual de nulidad, prevista en el artículo 87 del C.C.A., mientras que la reclamación laboral de los «funcionarios de hecho» se presenta a través de la acción de nulidad y restablecimiento del derecho en virtud del acto que, agotando vía gubernativa, niega los reconocimientos laborales (art. 85 C.C.A.).

De manera que habrá de establecerse si, requiriéndose pronunciamiento judicial expreso sobre la nulidad, en la reclamación laboral surgida de una forma de contratación estatal haya de acudirse ahora a la acción contractual.

El artículo 44 de la ley 80 de 1993 consagra la figura de la nulidad absoluta decretada de oficio, lo cual constituye una excepción al carácter rogado de la jurisdicción contenciosa administrativa, pues el juez puede pronunciarse sobre efectos no pretendidos por las partes, sin que ello represente un pronunciamiento ultrapetita.

Esta declaratoria oficiosa procede aún en acciones autónomas a la contractual, como sería el caso de la acción de nulidad y restablecimiento laboral a la que se lleve el análisis del contrato estatal anulable ${ }^{34}$, pues lo que procesalmente se exige es la identidad de partes y el análisis sobre la ilicitud de las cláusulas contractuales (art. 45 Ley 80/93). Pero, dado el carácter oficioso de su

\footnotetext{
${ }^{33}$ Figura especialmente contenida en el artículo 44 de la Ley 80 de 1993

34 En igual sentido, se cita: «Esta norma, de inusual ejercicio, podría aplicarse si por ejemplo, en un proceso de nulidad y restablecimiento de carácter laboral, el actor demuestra su calidad de «empleado público» no obstante que sus labores fueron desempeñadas en virtud de un contrato de prestación de servicios. En estas condiciones, por mandato del artículo 87, se debería declarar de oficio la nulidad de dicho contrato... «Vega de Herrera, Mariela. Manual de Procedimiento Contencioso Administrativo. Primera Edición, Editorial Leyer, 1999. Pág. 85.
} 
declaratoria, ¿qué sucede si el juez se niega a declararla?.

Si la causa se discute bajo la acción de nulidad y restablecimiento del derecho, la pretensión de nulidad absoluta del contrato no es propia del petitum, por lo que su formulación conlleva a la indebida acumulación de pretensiones, luego será necesario acudir a la acción contractual en donde la indemnización es consecuencia de la nulidad.

Esta acción contractual, autónoma y distinta a la de nulidad y restablecimiento del derecho, no exige el agotamiento previo de vía gubernativa, como sí la laboral, además versa sobre asuntos conciliables, y por lo tanto, tiene como requisito de procedibilidad, el haber agotado la conciliación prejudicial ${ }^{35}$, mientras que la discusión sobre la legalidad de un acto administrativo no es asunto objeto de conciliación.

Y para el caso del contratista que hubiere desarrollado actividades propias del trabajador oficial, siendo que la jurisdicción competente para resolver el conflicto es la ordinaria laboral (art. 4 C.S.T.), la discusión sobre la necesidad de anular el contrato conduce a la falta de jurisdicción del juez laboral, dada la atribución específica que el Código Contencioso Administrativo otorga al juez del contrato estatal en sus artículos 128 y siguientes.

En la legislación uruguaya, por ejemplo, el propio ordenamiento resuelve la situación, previendo que no se requiere seguir una acción específica de nulidad, pues se puede hacer valer en el propio proceso laboral, por lo que las estipulaciones contractuales sirven para probar la existencia de la relación entre las partes, y establecer las condiciones que puedan exceder el nivel mínimo de protección de las normas laborales ${ }^{36}$.

Concluyendo este punto, se considera que habrá de formularse la acción laboral ante la jurisdicción administrativa cuando las labores desempeñadas correspondan a las de un empleado público, y ante la jurisdicción ordinaria, si se trata de un trabajador oficial, independientemente de los vicios de nulidad que afecten el contrato estatal.

\section{La pretensión económica como aspecto diferente a la reparación del daño}

Sostiene la Sala Plena del Consejo de Estado en el fallo aquí analizado, que la

\footnotetext{
${ }^{35}$ Leyes 23 de 1991 y 446 de 1998

${ }^{36}$ PLÁ RODRÍGUEZ, Américo. Opus cítae.
} 
pretensión del pago de prestaciones laborales como las que se reconocen al empleado público no tiene el carácter de indemnización, que corresponde más a la pretensión contractual, por lo que el juez administrativo no puede decretarlo oficiosamente pues ello desconocería los principios de congruencia de la sentencia y el derecho de defensa del demandado.

La tesis minoritaria contradice la afirmación, aclarando que su jurisprudencia ha establecido que los pagos laborales adeudados se reconocen a título de indemnización, concepto que no difiere del restablecimiento del derecho. Se trata, pues, de una relación de género a especie.

Se agrega como argumento contrario a la tesis mayoritaria, que la pretendida indemnización se enmarca en el concepto amplificado de daño antijurídico previsto en el artículo 90 de la Constitución Política, independiente del tipo de acción -laboral, contractual o de reparación directa- que se plantee.

No se desconoce entonces, el derecho de defensa de la entidad demandada cuando desde la demanda la parte actora claramente determina su pretensión resarcitoria, y es precisamente sobre ésta que la demandada presenta su oposición.

La consideración del fallador desconoce su propia jurisprudencia cuando, reconociéndose su rol de facilitador para la eficacia del acceso a la justicia, aplica la doctrina del mecanismo de cierre del sistema de protección y garantía, puntualizando el carácter de la jurisdicción contencioso administrativa como el de una «justicia de tutela de derechos» ${ }^{37}$.

En el plano regional, por ejemplo, ante la actual reestructuración de la planta de personal del Departamento del Huila, parece haberse aplicado el criterio de que el contrato estatal puede suplir la relación laboral existente ante cargos suprimidos, pues en sentir de algunas autoridades departamentales, ello representa una mayor eficiencia, conforme a las declaraciones de prensa rendidas por el Secretario de Hacienda Departamental, Sr. Ramírez Cruz, que en lo pertinente se transcriben:

«En la actualidad la administración pública no se puede desgastar en hacer labores para las cuales han (sic) comprobado que no son eficientes. Por lo tanto, se tomará la decisión de contratar con particulares. Un ejemplo de lo anterior es analizar lo que pasó con la Secretaría de Obras Públicas, la cual se convirtió en administraciones anteriores en un desangre presupuesta!. Con su desaparición

\footnotetext{
${ }^{37}$ Consejo de Estado, Sección $2^{\text {a }}$. Auto 2072(23205) del 15 de mayo de 2003. Ponente: ALIER EDUARDO HERNÁNDEZ ENRIQUEZ. Actor: SOCIEDAD CIGARRERÍA PLAYA LTDA. Demandado: DEPARTAMENTO DE RISARALDA Y OTROS.
} 
en la pasada reestructuración administrativa, este trabajo lo hacen ahora particulares logrando mejores resultados que los que se originaban en ese tiempo» ${ }^{38}$.

En adelante, habida consideración del gran número de reclamaciones judiciales de tipo laboral sobre figurados contratos estatales de prestación de servicios, las tesis del Consejo de Estado aquí expuestas habrán de decantarse, y el papel de los profesionales del Derecho en este campo, será el de contribuir a una mejor solución a la problemática que la nueva doctrina presenta, más aún bajo las actuales políticas de «modernización del Estado» mediante la reestructuración de las plantas de personal de las entidades públicas.

\section{Adendo:}

En el tema de los servicios personales temporales, la recientemente expedida Ley 909 del 23 de septiembre de 2004, por la cual se expiden normas que regulan el empleo público, la carrera administrativa, y la gerencia pública, introdujo la novedad de los EMPLEOS DE CARÁCTER TEMPORAL, estableciéndose como una categoría especial, adicional a los empleos de carrera, de libre nombramiento y remoción y de periodo fijo (art. 1 de la Ley), que pueden crearse de manera excepcional, previa motivación técnica y disponibilidad presupuestal, cuyo diseño deberá incluir su duración (art. 19 num 2 literal c) idem) siempre que se trate de una de las siguientes condiciones (art. 21):

a) «Cumplir funciones que no realiza el personal de planta por no formar parte de las actividades permanentes de la administración;

b) Desarrollar programas o proyectos de duración determinada;

c) Suplir necesidades de personal por sobrecarga de trabajo, determinada por hechos excepcionales;

d) Desarrollar labores de consultoría y asesoría institucional de duración total, no superior a 12 meses y que guarde relación directa con el objeto y la naturaleza de la institución».

Esta figura no está consagrada en la clasificación constitucional del artículo 123 C.P., y su antecedente normativo sería la del supernumerario (art. 83 Decreto 1042 de 1978), vinculado temporal u ocasionalmente hasta por tres meses prorrogables con autorización del gobierno nacional según la naturaleza de las actividades.

La nueva modalidad implica un avance en el reconocimiento de los derechos

${ }^{38}$ Periódico Regional «La Nación», Neiva, Lunes 04 de octubre de 2004, página 17. 
salariales y prestacionales de quien desarrolle tales actividades TRANSITORIAS, que como tal, no le otorgan al servidor los derechos inherentes al sistema de la carrera administrativa (entre ellos la estabilidad), resuelve la problemática de las necesidades temporales de las entidades estatales en materia de función pública, pero, como lo advierte la misma norma, se trata de situaciones excepcionales y temporales, de modo que no podrá utilizarse esta figura para la permanencia de un «empleo temporal» ejercido transitoriamente por distintos servidores, que al final se convierta en permanente. 